\title{
Chemotherapy-induced ovarian toxicity in patients affected by endocrine-responsive early breast cancer
}

\author{
Francesco Torino ${ }^{\mathrm{a}}$, Agnese Barnabei ${ }^{\mathrm{b}}$, Liana De Vecchis ${ }^{\mathrm{a}}$, Valentina Sini ${ }^{\mathrm{c}}$, \\ Francesco Schittulli ${ }^{\mathrm{d}}$, Paolo Marchetti ${ }^{\mathrm{e}}$, Salvatore Maria Corsello ${ }^{\mathrm{f}, *}$ \\ ${ }^{a}$ Department of Systems Medicine, Chair of Medical Oncology, Tor Vergata University of Rome, Italy \\ ${ }^{\mathrm{b}}$ Endocrinology Unit, Regina Elena National Cancer Institute, Rome, Italy \\ c Surgical and Medical Department of Clinical Sciences, Biomedical Technologies and Translational Medicine, "Sapienza" \\ University of Rome, Italy \\ d Department of Women's Health, Cancer Institute of Bari, Italy \\ e Department of Clinical and Molecular Medicine, Medical Oncology Division, Sant'Andrea Hospital, "Sapienza" \\ University of Rome and IDI-IRCCS, Rome, Italy \\ ${ }^{\mathrm{f}}$ Endocrinology Unit, Università Cattolica, Rome, Italy
}

Accepted 18 July 2013

\section{Contents}

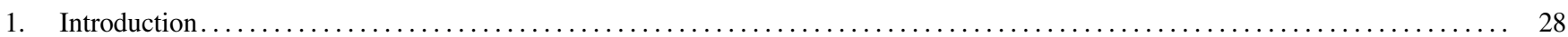

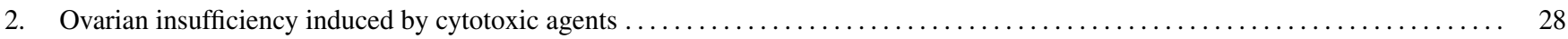

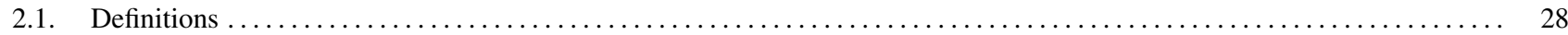

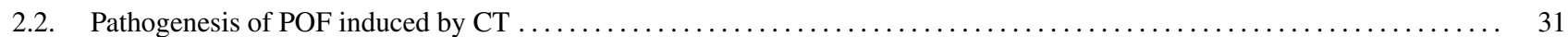

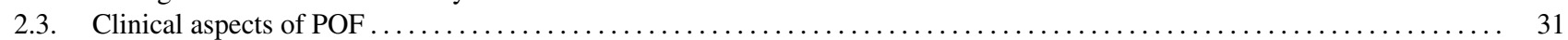

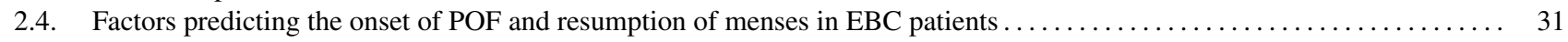

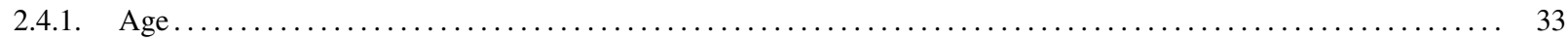

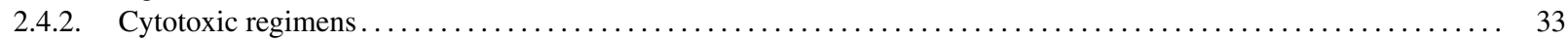

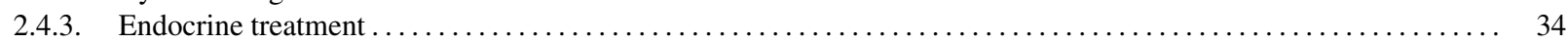

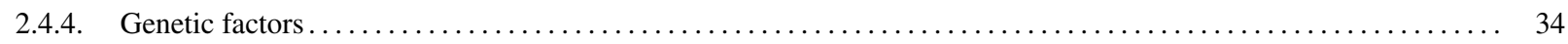

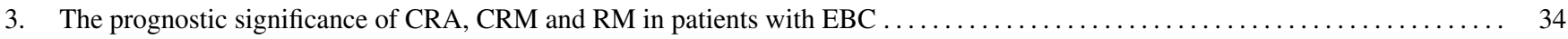

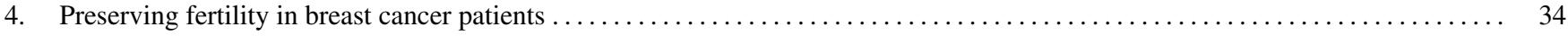

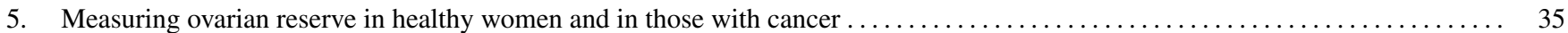

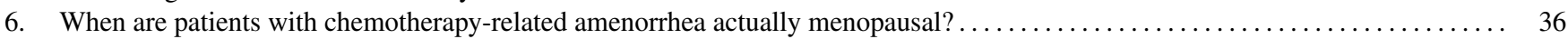

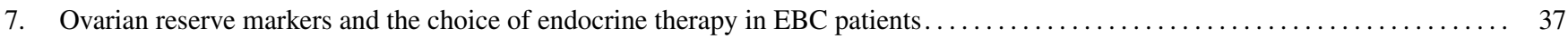

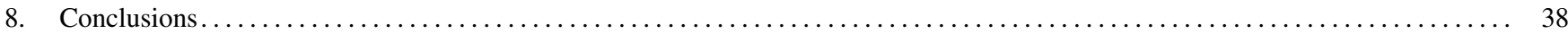

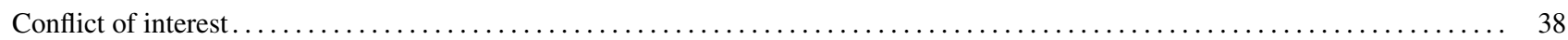

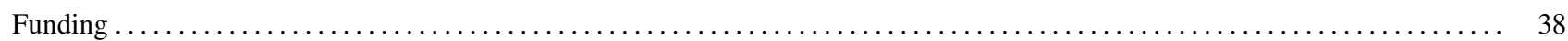

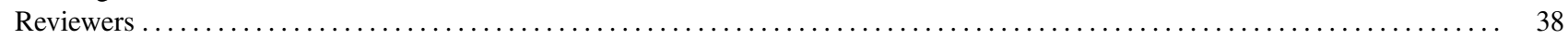

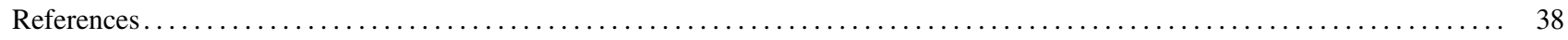

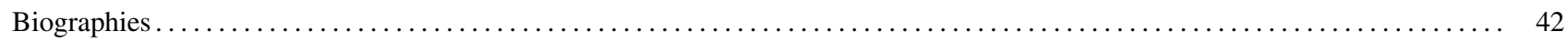

\section{Abstract}

Cytotoxic chemotherapy may variably affect ovarian function depending on age and ovarian reserve at diagnosis, type of chemotherapy and use of tamoxifen.

Ascertaining whether a premenopausal patient with endocrine-responsive early breast cancer and chemotherapy-induced amenorrhea has reached menopause is essential not only in order to provide accurate information on residual fertility, but also to appropriately prescribe

\footnotetext{
* Corresponding author at: Largo A. Gemelli, 8, I-00168 Rome, Italy. Tel.: +39 06 3219418; fax: +39 0632500063.

E-mail address: corsello.sm@mclink.it (S.M. Corsello).
} 
endocrine therapy. Indeed, aromatase inhibitors are contraindicated in women with residual ovarian reserve. However, the diagnosis of menopause in patients with chemotherapy-induced amenorrhea is challenging, since clinical features, follicle-stimulating hormone and estradiol levels may be inaccurate to this aim. Recent studies demonstrated that the anti-müllerian hormone may improve the assessment of ovarian reserve residual to chemotherapy in women with early breast cancer.

Herein, we review the incidence of amenorrhea and menopause induced by cytotoxic chemotherapy in women affected by early breast cancer and the suggested mechanisms that sustain these side-effects. Furthermore, it has been scrutinized the potential of new markers of ovarian reserve that may facilitate the selection of appropriate endocrine treatment for premenopausal women who develop amenorrhea following adjuvant chemotherapy for early breast cancer.

(C) 2013 Elsevier Ireland Ltd. All rights reserved.

Keywords: Breast cancer; Chemotherapy-induced amenorrhea; Chemotherapy-induced menopause; Aromatase inhibitors; Ovarian reserve

\section{Introduction}

Breast cancer $(\mathrm{BC})$ is the second most common cancer in Western Countries and the most common invasive malignancy in reproductive-aged women [1,2]. Approximately $30 \%$ of patients are premenopausal and $10 \%$ are aged $35-44$ at diagnosis [3]. Despite the fact that BC in women under the age of 40 is infrequent (5.5\% in the United States) [4], a dramatic increase in the number of $\mathrm{BC}$ diagnosed in premenopausal women has been reported in several countries [5]. $\mathrm{BC}$, even in early stages (EBC), presents more aggressive features, and prognosis is poorer in younger compared with older women [6-8]. Therefore, most of these patients receive adjuvant cytotoxic treatments (CT) followed by endocrine therapy (ET) in the case of endocrine-responsive (ER+) disease $[9,10]$.

CT prolongs survival of patients affected by EBC, even in the case of endocrine-responsive disease, particularly in women under 50 [11]. However, in a variable percentage of pre-/perimenopausal patients CT may cause amenorrhea (chemotherapy-related amenorrhea, CRA) or menopause (chemotherapy-related menopause, CRM). These sideeffects are predictive of improved clinical outcomes in most clinical trials $[12,13]$, but expose women to a number of physical and socio-psychological distresses regarding residual fertility, sexual dysfunction, bone loss and menopausal symptoms, with a markedly negative effect on quality of life [14].

A number of factors influence the onset of CRA/CRM, including age, type of CT received and use of tamoxifen (Table 1). Estimation of the individual risk to develop CRA or CRM, however, remains approximate.

Nowadays, to ascertain whether a patient with endocrineresponsive EBC and CRA is actually menopausal is of utmost importance not only in order to provide accurate information on residual fertility, but also for prescribing the most suitable ET (i.e., tamoxifen or aromatase inhibitors, AI). Indeed, only in postmenopausal patients are AI recommended as upfront treatment, or sequentially after tamoxifen, since they reduce the risk of recurrence [16]. Instead, AI as single agents are contraindicated in premenopausal patients and in those presenting residual ovarian function [16]. In these patients, the inappropriate use of AI induces a temporary inhibition of estrogen production, leading to a feedback increase in gonadotropin levels, which, in turn, stimulate follicular growth, aromatase activity and restoration of pre-CT estradiol levels [17]. These changes in hormonal levels would be expected to reduce or abolish the efficacy of the anticancer treatment received and expose patients to further unjustified side-effects, including pain from ovarian hyperstimulation and increased risk of unplanned pregnancy [18]. Confirmation of the menopausal status is, therefore, mandatory before prescribing AI [19].

In current clinical practice, menopause in a patient with CRA may be only presumed based on some clinical features, such as age, the likelihood of gonadal toxicity from chemotherapy, use of tamoxifen, menstrual history, vasomotory symptoms, together with serum levels of FSH and estradiol. Information obtained by these parameters, however, may be misleading. In particular, serum levels of FSH and estradiol, widely used to confirm menopausal status, may provide erroneous information in $25-35 \%$ of cases $[18,20]$.

This article reviews the incidence and the pathophysiology of gonadal damage induced by CT in women affected by endocrine-responsive EBC. Moreover, practical approaches integrating new markers of ovarian reserve are proposed to distinguish truly menopausal women who may receive an AI as adjuvant ET from those with CRA.

\section{Ovarian insufficiency induced by cytotoxic agents}

\subsection{Definitions}

The progressive loss of oocytes from fetal life through menopause is physiological [21]. At approximately the age of 37, however, an accelerated atresia of the oocytes is responsible for the average age of menopause being about 51 years (range 40-60 years) in Western women $[14,21,22]$. Cessation of menses that occurs before the age of 45 is defined as "early" menopause. When menses cease even earlier (before the age of 40), it is called "premature" menopause or premature ovarian failure (POF). The latter is an arbitrary cut-off point designated by the World Health Organization (WHO) corresponding to menopause occurring at an age two standard deviations below the population mean [23]. Instead, there is no WHO proposed definition for early menopause, which is, however, largely used in several studies. 
Table 1

Rate of chemotherapy-related amenorrhea and resumption of menses in selected trials of cytotoxic chemotherapy including only women affected by early breast cancer.

\begin{tabular}{|c|c|c|c|c|c|c|c|c|}
\hline \multirow[t]{2}{*}{ Authors } & \multirow[t]{2}{*}{$\mathrm{CT}$ regimen } & \multirow[t]{2}{*}{ No. patients } & \multirow{2}{*}{$\begin{array}{l}\text { CRA definition } \\
\text { (duration) }\end{array}$} & \multirow{2}{*}{$\begin{array}{l}\text { Median age } \\
\text { (range; yrs) }\end{array}$} & \multirow{2}{*}{$\begin{array}{l}\text { Median follow-up } \\
\text { (range; mos) }\end{array}$} & \multicolumn{2}{|c|}{ CRA $(\%)$} & \multirow{2}{*}{$\begin{array}{l}\text { Resumption of } \\
\text { menses (\%) }\end{array}$} \\
\hline & & & & & & $<40 \mathrm{yrs}$ & $\geq 40 \mathrm{yrs}$ & \\
\hline \multirow[t]{3}{*}{ Goldhirsch et al. [56] } & $\mathrm{CMF}(400 \mathrm{mg} / \mathrm{mq}, 1)$ & 541 & & & & 10 & 33 & \\
\hline & Classic $\mathrm{CMF} \times 6$ & 387 & $<9 \mathrm{mos}$ & NA & NA & 33 & 81 & NA \\
\hline & Classic $\mathrm{CMF} \times 12$ & 399 & & & & 61 & 95 & \\
\hline \multirow[t]{2}{*}{ Venturini et al. [58] } & FEC21 & 250 & & & $123\left(48_{-144)}\right.$ & & 64 & \\
\hline & FEC14 & 253 & $>3 \mathrm{mos}$ & NA & $123(48-144)$ & & 64 & NA \\
\hline \multirow[t]{2}{*}{ Jung et al. [70] } & $\mathrm{CMF}$ & 188 & & & 109.8 & & 43 & 12.5 \\
\hline & FAC & 53 & $\geq 6 \mathrm{mos}$ & $40(25-53)$ & (16.6-193) & & $65.2 p=n s$ & 3.3 \\
\hline \multirow[t]{3}{*}{ Parulekar et al. [79] } & CMF & 236 & & $438(23-55)$ & $114(3-145)$ & & 71 & NA \\
\hline & $\mathrm{CEF}$ & 224 & $\geq 3 \mathrm{mos}$ & $43.8(23-55)$ & $114(3-145)$ & 76 & & \\
\hline & & & & & & $p=n s$ & & \\
\hline \multirow[t]{4}{*}{ Di Cosimo et al. [60] } & $\mathrm{CMF}$ & 19 & & & & & 47.4 & \\
\hline & CMF-ED & 10 & & $42(27-51)$ & & & 58 & \\
\hline & FEC/EC & 43 & $\geq 3 \mathrm{mos}$ & $42(27-51)$ & NA & & 45.2 & Overall 7.2 \\
\hline & E/E-CMF & 39 & & & & & $p=n s$ & \\
\hline \multirow[t]{3}{*}{ Martin et al. [47] } & FAC & 403 & & & & & 52.4 & \\
\hline & TAC & 420 & $>3 \mathrm{mos}$ & $49(23-70)$ & 55 & & 61.7 & NA \\
\hline & & & & & & & $p=.0007$ & \\
\hline Fornier et al. [49] & AC- $\mathrm{T}$ & 166 & $>12 \mathrm{mos}$ & $36(27-40)$ & $37.9(12.2-77.8)$ & & 15 & 85 \\
\hline \multirow[t]{3}{*}{ Tham et al. [45] } & $\mathrm{AC}$ & 75 & & & & & 55 & 12 \\
\hline & AC-T & 116 & $\geq 3 \mathrm{mos}$ & NA & NA & & 64 & 28 \\
\hline & & & & & & & $p=n s$ & $p=n s$ \\
\hline \multirow[t]{3}{*}{ Berliere et al. [51] } & FEC & 84 & & 43.5 & & & 92.5 & 23.7 \\
\hline & FEC-D & 70 & $<12 \mathrm{mos}$ & 44 & 79 & & 93 & 36.5 \\
\hline & & & & & & & $p=n s$ & $p=.019$ \\
\hline \multirow[t]{3}{*}{ Pérez-Fidalgo et al. [53] } & A-based & 212 & & 44 & & & 75.5 & \\
\hline & TXs-based & 93 & $\geq 12 \mathrm{mos}$ & $43(29-53)$ & NA & & 82.7 & Overall 6.3 \\
\hline & & & & & & & $p=n s$ & \\
\hline \multirow[t]{3}{*}{ Ganz et al. [55] } & AT & 752 & & 50 & & & 47.1 & \\
\hline & TAC & 705 & $\geq 6 \mathrm{mos}$ & 51 & NA $(6-24+)$ & & 67.2 & NA \\
\hline & AC-T & 692 & & 51 & & & 83.3 & \\
\hline \multirow[t]{6}{*}{ Petrek et al. [61] } & $\mathrm{AC}$ & 120 & & & & & 53 & \\
\hline & $\mathrm{ACT}$ & 168 & & & & & 42 & \\
\hline & $\mathrm{CMF}$ & 83 & & $305(20-15)$ & $\mathrm{NA}(1-60+1)$ & & 82 & \\
\hline & FAC & 38 & NA & $39.5(20-45)$ & $\mathrm{NA}(1-60+)$ & & NA & NA \\
\hline & FACT & 34 & & & & & NA & \\
\hline & TAC & 19 & & & & & 45 & \\
\hline \multirow[t]{4}{*}{ Sukumvanich et al. [62] } & $\mathrm{CMF}$ & 76 & & & & & 34 & 23 \\
\hline & (F)AC & 146 & & & & & 37 & 68 \\
\hline & (F)ACT & 188 & $\geq 6 \mathrm{mos}$ & $39(20-45)$ & $>24(6-60+)$ & & 45 & 57 \\
\hline & & & & & & & & $p=.002$ \\
\hline \multirow[t]{3}{*}{ Najafi et al. [48] } & $\mathrm{CMF}$ & 40 & & & & & 52.5 & 19.1 \\
\hline & $\mathrm{AC} / \mathrm{CAF}$ & 111 & $\geq 6 \mathrm{mos}$ & $40.9 \pm 6.8$ & $36(12-120)$ & & 66.7 & 27.1 \\
\hline & ACT/AC-T & 75 & & & & & 78.7 & 49.1 \\
\hline
\end{tabular}




\begin{tabular}{|c|c|c|c|c|c|c|c|c|}
\hline \multirow[t]{2}{*}{ Authors } & \multirow[t]{2}{*}{ CT regimen } & \multirow[t]{2}{*}{ No. patients } & \multirow{2}{*}{$\begin{array}{l}\text { CRA definition } \\
\text { (duration) }\end{array}$} & \multirow{2}{*}{$\begin{array}{l}\text { Median age } \\
\text { (range; yrs) }\end{array}$} & \multirow{2}{*}{$\begin{array}{l}\text { Median follow-up } \\
\text { (range; mos) }\end{array}$} & \multicolumn{2}{|l|}{ CRA $(\%)$} & \multirow{2}{*}{$\begin{array}{l}\text { Resumption of } \\
\text { menses (\%) }\end{array}$} \\
\hline & & & & & & $<40 \mathrm{yrs}$ & $\geq 40 \mathrm{yrs}$ & \\
\hline \multirow[t]{4}{*}{ Lee et al. [52] } & $\mathrm{AC} / \mathrm{FAC}$ & 154 & \multirow{4}{*}{$\geq 6 \mathrm{mos}$} & \multirow{4}{*}{$42(22-50)$} & \multirow{4}{*}{$37(12-80)$} & & 57 & \multirow{4}{*}{ Overall 14} \\
\hline & FAC-T/ACT & 148 & & & & & 58 & \\
\hline & $\mathrm{CMF}$ & 24 & & & & & 56 & \\
\hline & & & & & & & $p=n s$ & \\
\hline \multirow[t]{4}{*}{ Abusief et al. [59] } & $\mathrm{AC}$ & 228 & \multirow{4}{*}{$\geq 6 \mathrm{mos}$} & \multirow{4}{*}{$43(25-55)$} & \multirow{4}{*}{$33(6-114)$} & & 54.8 & \multirow{4}{*}{ NA } \\
\hline & AC-T & 183 & & & & & 56.4 & \\
\hline & $\mathrm{AC}-\mathrm{T}$ (DD) & 120 & & & & & 58.7 & \\
\hline & $\mathrm{AC}-\mathrm{T}+\mathrm{H}$ & 39 & & & & & 46.1 & \\
\hline \multirow[t]{3}{*}{ Han et al. [46] } & TX vs AC & 122 & \multirow{3}{*}{$>3 \mathrm{mos}$} & \multirow{3}{*}{$40(21-50)$} & \multirow{3}{*}{$40(18.8-69.3)$} & & 90.2 & 33.9 \\
\hline & AC-T & 34 & & & & & 73.5 & 23.2 \\
\hline & FAC & 129 & & & & & 72.1 & $p=n s$ \\
\hline \multirow[t]{3}{*}{ Zhou et al. [50] } & FEC & 78 & \multirow{3}{*}{$\geq 12 \mathrm{mos}$} & \multirow{3}{*}{$\begin{array}{l}42.5(23-53) \\
\text { Mean }\end{array}$} & \multirow{3}{*}{$38.5(17-83)$} & & 44.9 & \multirow{3}{*}{ NA } \\
\hline & $\mathrm{TE}$ & 66 & & & & & 30.3 & \\
\hline & $\mathrm{NE}$ & 26 & & & & & 23.1 & \\
\hline \multirow[t]{2}{*}{ Gerber et al. [64] } & $\mathrm{AC} \pm \mathrm{T}$ & 30 & \multirow[b]{2}{*}{$6 \mathrm{mos}$} & $38.5(29-47)$ & & & 93.3 & 56.7 \\
\hline & $\mathrm{AC} \pm \mathrm{T}+$ Goserelin & 30 & & $\begin{array}{l}35(26-44) \\
p=.092\end{array}$ & $24+$ & & 83.3 & $\begin{array}{l}70 \\
p=.284\end{array}$ \\
\hline Wong et al. [88] & $\mathrm{AC} / \mathrm{EC} \pm \mathrm{TXs} / \mathrm{FEC}+$ Goserelin & 132 & NA & $35(20-45)$ & $58(4-119)$ & & & $91(<35 \mathrm{yrs})$ \\
\hline Badawy et al. [89] & FAC & 39 & & $30 \pm 3.51$ & & & 76.7 & 33.3 \\
\hline & $\mathrm{FAC}+$ Goserelin & 39 & NA & $\begin{array}{l}29.2 \pm 2.93 \\
p=.76\end{array}$ & 8 (all patients) & & 11.4 & $\begin{array}{l}89.6 \\
p=.001\end{array}$ \\
\hline Munster et al. [65] & $\mathrm{CT}(\mathrm{AC} \pm \mathrm{T} / \mathrm{FEC} / \mathrm{FAC})$ & 21 & & $38(26-44)$ & & & 9.5 & 90.5 \\
\hline & $\mathrm{CT}+$ Triptorelin & 26 & NA & $39(21-44$ & $18(5-43)$ & & 11.6 & 88.4 \\
\hline & & & & & & & $p=n s$ & $p=.36$ \\
\hline Del Mastro et al. [63] & CT alone & 133 & & $39(25-45)$ & & & CRM & 49.6 \\
\hline & $\mathrm{CT}+$ Triptorelin & 148 & CRM ( 8$)$ & $39(24-45)$ & & & 25.9 & 63.3 \\
\hline & & & CRIM (3) & & $24+$ & & 8.9 & $p=.03$ \\
\hline & & & & & & & $p<.001$ & \\
\hline Leonard et al. [90] & $\mathrm{A} \pm \mathrm{C} \pm \mathrm{TXs}+$ Goserelin & $<40$ yrs: 87 & & & & & No resu & enses \\
\hline & & $>40$ yrs: 53 & & & $12+($ all & & & \\
\hline & & & 12 & NA & patients) & & & \\
\hline & & & & & & & & \\
\hline
\end{tabular}

Definition of chemotherapy-related amenorrhea (CRA): absence of menses lasting for the indicated period of time; A = adriamycin; AC: adriamycin, cyclophosphamide; AT: adriamycin, docetaxel; CMF: cyclophosphamide, methotrexate, 5-fluorouracil; $\mathrm{C}=$ cyclophosphamide; $\mathrm{CRM}$ : chemotherapy-related menopause; $\mathrm{CEF}$ : cyclophosphamide, epirubicin, 5-fluorouracil; $\mathrm{CT}$ : cytotoxic chemotherapy; $\mathrm{D}=$ docetaxel; $\mathrm{DD}=$ dose dense regimen; EC = epirubicin, cyclophosphamide; FAC: 5-fluorouracil, adriamycin, cyclophosphamide; FACT: 5-fluorouracil, adriamycin, cyclophosphamide, paclitaxel; FEC: 5-fluorouracil, epirubicin, cyclophosphamide; mos = months; $\mathrm{N}=$ navelbine; $\mathrm{NA}=$ not available; TAC: docetaxel, adriamycin, cyclophosphamide; $\mathrm{T}=$ paclitaxel; $\mathrm{TX} s=$ taxanes; $\mathrm{X}=$ capecitabine; vs: versus; yrs =years. $(\S)$ CRM: no resumption of menstrual activity and postmenopausal levels of follicle-stimulating hormone and estradiol 1 year after the last cycle of chemotherapy. 
Table 2

Estimated risk of permanent amenorrhea resulting from single agent chemotherapy and combination regimens used as adjuvant treatment for early breast cancer.

\begin{tabular}{lll}
\hline & Single drug & Adjuvant regimens \\
\hline High risk $(>80 \%)$ & $\begin{array}{l}\text { Cyclophosphamide } \\
\text { Ifosfamide }\end{array}$ & \\
& $\begin{array}{l}\text { Chlorambucil } \\
\text { Melphalan, } \\
\text { busulfan } \\
\text { Nitrogen mustard }\end{array}$ & \\
& $\begin{array}{l}\text { Procarbazine } \\
\text { thiotepa }\end{array}$ & \\
in women aged $\geq 40$ years
\end{tabular}

Modified from Ref. [107].

POF refers to primary ovarian insufficiency, in which the cause of ovarian dysfunction is inherent in the ovary [24]. There is debate within the literature as to whether POF should refer only to spontaneous cessation of ovarian function and exclude induced ovarian failure.

\subsection{Pathogenesis of POF induced by $C T$}

POF caused by CT can arise through impairment of follicular maturation or primordial follicle depletion, or both $[3,25]$. Ovaries are variably sensitive to most cytotoxic drugs (Table 2) [26]. Alkylating agents are most commonly associated with permanent and irreversible gonadal damage, presumably because these drugs are not cell cycle-specific. Therefore, both resting and growing primordial follicles can be damaged $[25,26]$. Cycle-specific agents, such as methotrexate, 5-fluorouracil, bleomycin and vinca alkaloids are associated with mild or no gonadotoxicity. Cisplatin and adriamycin modestly affect ovarian function.

Chemotherapy-induced ovarian damage resembles accelerated ovarian aging $[3,24,27]$. Pathologic features associated with this type of POF mainly include reduction in the follicle pool, with follicular apoptosis, premature atresia, harmed blood vasculature and cortical fibrosis, eventually leading to ovarian atrophy $[27,28]$.

Currently, several mechanisms have been proposed to explain the damage induced by cytotoxic agents to the ovaries, thoroughly reviewed in $[29,30]$ and summarized in Table 3. Presumably, different classes of anticancer drugs act through a range of mechanisms, possibly targeting different ovarian cells [29]. Oocyte apoptotic death could be the consequence of the direct damage to the oocyte itself, to somatic cells, or both. This, in turn, stimulates primordial follicles to grow to replace growing follicles, but reduces the primordial pool of resting follicles (the "burn-out" hypothesis) [27]. Recently, a correlation between acute vascular damage and alteration in ovarian blood flow, size, and function, associated with an abnormal hormonal profile and clinical symptoms, was demonstrated in a small cohort of 20 premenopausal patients with EBC who were treated with neoadjuvant/adjuvant CT [31]. Notably, the observed pattern of acute ovarian failure was similar and homogeneous in all patients, despite age and variability in CT-regimens.

\subsection{Clinical aspects of POF}

The clinical degree of ovarian dysfunction (i.e., oligomenorrhea, transient/prolonged amenorrhea, and true menopause) is essentially related to the extent of injury caused by CT. Oligomenorrhea or temporary amenorrhea are the consequence of damage to both steroid-producing cells (granulosa cells and theca cells) and the oocytes of growing follicles. When exposure to CT induces near complete follicular depletion or few follicles remain viable (approximately $<1000$ ), periods may cease and menopause will occur $[14,32]$. Despite the fact that many patients $>40$ years of age develop CRA, ovarian failure may be temporary in a considerable number of women. It is not yet known what percentage of women with CRA/oligomenorrhea will later develop CRM. The remaining follicles, however, may still be recruited from the primordial pool. Accordingly, gonadotropin levels may return to normal, menstrual cycles may resume and/or fertility may recover months to years after withdrawal/end of CT [26]. Menses are more likely to return in younger women, in those receiving less gonadotoxic regimens and, in any case, in those with a higher basal number of follicles $[12,14]$.

Women who continue to menstruate following CTregimen may have a reduced likelihood of pregnancy, even if menses are regular [33-35]. Women with temporary CRA present an increased risk of CRM compared to those who continue to menstruate throughout treatment [36].

\subsection{Factors predicting the onset of $P O F$ and resumption of menses in EBC patients}

The loss or impairment of ovarian function as side effects of adjuvant CT have been extensively studied in patients affected by EBC. In these patients, a few variables mainly influence the risk of POF induced by CT: the age of a patient when she commences CT and the type and the doses of the prescribed CT $[24,37,38]$. Furthermore, tamoxifen may variably affect the onset of POF in premenopausal patients with endocrine-responsive EBC. Recently, the 
Table 3

Overview of preclinical pathogenic evidence on ovarian toxicity induced by anticancer drugs available for the treatment of patients affected by breast cancer.

Drugs $\quad \begin{aligned} & \text { Types of ovary cells } \\ & \text { targeted }\end{aligned}$

Cyclophosphamide (alkylating agenst?)

Oocytes/PMF

GCs

Stromal cells/vessels

Platinum compounds

Oocytes/PMF

GCs/TCs

Doxorubicin (anthracyclines)

GCs

Stromal cells/vessels

Taxanes

Mature follicles

5-Fluorouracil
Oocytes/PMF
In human fetal ovary exposed to CTX, apoptosis was shown before in oocytes (PMF), than GCs

CTX metabolites induce H2AX, a marker of double strand DNA breaks predominantly in mouse oocytes (but also in GCs) cultured in vitro In the GCs of rat ovaries CTX damage to mitochondria induce the release of the cytocrome $\mathrm{C}$ into cytoplasm leading to cell apoptosis mediated by caspase family proteins. Damage in human GCs nuclei and follicular basement membranes

Oxidative stress has been associated with CTX toxicity in GCs of mature follicles. CTX induces depletion in glutathione and rise in reactive oxygen species mediating apoptosis in GCs

In human ovaries severe signs of stromal fibrosis and capillary changes or cortical fibrosis and blood vessel damage were found following regimens including alkylating agents

Experimental studies on platinum-induced ovarian toxicity limited to cisplatin. Pre-granulosa cell cytoplasmic and nuclear swelling followed by PMF architecture disruption with disappearance of the lumen and its oocyte. In rats cisplatin induces reduction in ovulation rate and a decline in $\mathrm{AMH}$ and inhibin-A After cisplatin exposure, decline in the level of hyperpolarization-activated cation channels in rat oocytes, GCs and TCs may contribute to decreased ovarian function

Another proposed mechanism for cisplatin-induced ovarian toxicity is the accumulation of or activation of p63, a member of p53 family, eventually leading to oocyte death

Doxorubicin induces apoptosis in mammalian oocytes and significantly decreases their survival in vitro. Several molecular pathways are involved in apoptosis of oocytes, including damage to chromosomes, activation of mitochondria and elevation of superoxides that induces endoplasmic reticulum stress with the increase in intracellular $\mathrm{Ca}^{++}$. This cascade in turn leads to apoptosis via calpain and caspase 12

DNA damage and apoptotic cell death induced by doxorubicin has been demonstrated both in human primordial follicles and GCs in vitro

Acute reduction in ovarian blood flow and disintegration of the vessel wall following in vivo administration of doxorubicin

Only preclinical studies on taxane-induced ovarian toxicity are available, limiting to paclitaxel. The drug induces apoptosis mainly in mature follicles and to a lesser extent in less mature populations; also estradiol serum levels were reduced by the drug

Ovarian function in mice may be affected (reduced fertility) when the drug is administered during the immediate postovulatory phase, but not during the other phases of fertility cycle
[121]

[32,33,122-129]

$[34,35,130,131]$

[27,126]

[130-133]

AMH, anti-müllerian hormone; ECs, endothelial cells; GCs, granulosa cells; PMF, primordial follicles; TCs, theca cells. 
potential role of genetic marker as a predictive factor of ovarian toxicity has emerged [28]. Notably, comparisons of POF rates between studies are hampered by substantial variability in treatment used, median age of patients, prevalence of endocrine-responsive disease, and follow-up duration. Inconsistencies also exist in the manner of reporting the incidence of CRA, and even in the definition of CRA. Some authors report the incidence of amenorrhea upon completion of chemotherapy, while others report continued amenorrhea at various points of time after the start of chemotherapy. In studies on adjuvant treatment for BC, the definition of CRA may vary from the absence of menses for at least 3 months to more than 1 year (Table 1 ).

\subsubsection{Age}

Age is currently the most relevant biological factor influencing the risk of CRM/CRA [12]. The occurrence of CRM in patients with EBC has been specifically evaluated in very few studies $[39,40]$. It has been reported in $22-61 \%$ of women aged $<40$ and $61-97 \%$ in those $>40$ years $[3,39,41]$. In this group of patients, the incidence of CRA has been more extensively evaluated (Table 1). By maintaining the arbitrary cut-off value of 40 years of age, rates of CRA may range from 49 to $100 \%$ in women $>40$ years, and from 10 to $71 \%$ in younger women $[3,12]$.

Resumption of menses (ReMen) in patients affected by $\mathrm{EBC}$ and CRA has been reported in $11 \%$ of those aged $>40$ years and $22-56 \%$ of those aged $<40$ years, respectively [3]. Analysis of ReMen in the IBCSG study VI population (in which patients received 3-9 cycles of CMF) indicated a recovery rate of $43 \%$ in patients under 40 , and of $9 \%$ in those aged 40 years and over [42]. In the NSABP B30 study (708 patients receiving 4 cycles of AC and 4 cycles of docetaxel) ReMen occurred within 24 months in $45.3 \%$ of patients aged under $40,10.9 \%$ of those aged $40-50$ and in $3.2 \%$ of patients aged over 50 [43].

\subsubsection{Cytotoxic regimens}

Other than age, the incidence of CRM/CRA mainly depends on the type of CT and the schedule of administration used (Table 1) [39,44]. However, further factors related to CT delivery may influence the onset of POF, including the combination of more than one drug (poly-CT), the cumulative dose of alkylating agents, and the phase of the menstrual cycle when CT is delivered. In women candidate to adjuvant $\mathrm{CT}$ for $\mathrm{EBC}$, the most commonly used CT-regimens incorporate multiple agents that are generally responsible for a more negative impact on ovarian activity, compared with monochemotherapy $[3,26,39]$. Higher cumulative doses of alkylating agents are associated with the highest risk of CRM, particularly in older premenopausal patients $[32,45,46]$. Similarly, patients who received higher cumulative doses of cyclophosphamide, such as with CMF and CEF/CAF-type regimens, showed a higher rate of transient and prolonged amenorrhea, compared to AC [3]. The influence of taxanes on the risk of CRA has been evaluated in several studies, but remains controversial. When taxanes are added to standard regimens, the risk of CRA increases in the majority of [45-50], but not in all, trials [51-54]. However, the extra-risk of CRA associated with these drugs is transient, being limited to 12 months following the end of CT. When CRA rates were evaluated in a comparison between AC followed by docetaxel, TAC or AT, the latter regimen led to the lowest CRA rate $(69.8 \%, 57.7 \%, 37.9 \%$, respectively) [55]. Higher doses and longer duration of CT-regimens may result in higher rates of CRA [56,57]. In two studies evaluating dose-dense FEC and AC-T, respectively, the incidence of CRA was identical in both the control and intensified arms (Table 1) $[58,59]$. However, definitive data regarding the effect of dose-dense therapy on rates of CRA are lacking. The specific impact of taxanes on the development of CRM is still unclear. Finally, when CT-regimens are administered during the follicular phase of the menstrual cycle they may increase the risk of ovarian toxicity $[3,12,60]$.

According to CT-regimen, ReMen may occur early or may be delayed even after 2-3 years from the onset of CRA. In a large prospective study investigating factors affecting the maintenance of menstrual bleeding (595 patients affected by EBC; CT-regimens: FAC, AC \pm taxanes or CMF), women receiving $\mathrm{CMF}$ were more likely to bleed during the first month after chemotherapy than women on ACcontaining regimens, but, by one year and thereafter, these women were less likely to bleed than those who received AC-regimens. Adding taxanes resulted in a further reduction of monthly bleeding [61]. Recently, the same group reported results in a cohort of 466 premenopausal patients (20-45 years) receiving CT (AC/ACT or CMF) for EBC. Of these, $41 \%$ and 29\% experienced CRA, respectively, after 6 and 12 months. In both groups, approximately $50 \%$ of patients resumed bleeding within 3 years. ReMen differed significantly according to treatment after 6 months of CRA (AC $68 \%$, ACT 57\%, CMF 23\%), but not after one year. After 2-year CRA, none of the patients who had received CMF experienced ReMen, compared with almost $25 \%$ of those treated with AC-based regimens [62]. In the study of Abusief et al. [59], which included 431 patients treated with doxorubicin and cyclophosphamide, with or without paclitaxel, ReMen between 6 and 12 months following completion of chemotherapy was reported in $14 \%$ and after $>12$ months in an additional $3 \%$ of cases.

Recently, a number of Phase III Trials evaluated the protective role of gonadothropin-releasing hormone $(\mathrm{GnRH})$ agonists in patients affected by EBC (see below). Since in these studies the primary end-point was the ovarian function after CT, the rates of CRA/CRM in the control group may represent a more reliable estimation of CTinduced ovarian toxicity. In a study by Del Mastro et al. [63] on 281 patients (age $\leq 45$ years; CT-regimens were anthracycline-based, anthracycline plus taxane-based, or CMF-based \pm triptorelin), CRA and CRM rates were $75.5 \%$ and $25.9 \%$, respectively. ReMen was reported by $49.6 \%$ of patients enrolled in the control group [63]. In the study 
by Gerber et al. [64] on 60 patients under the age of 46 (CT-regimens: AC with or without taxane \pm goserelin), at 6 months after CT the rate of temporary CRA was $83.3 \%$ with ReMen in $56.7 \%$ of patients in the control group. Lower rates of CRA/CRM were reported by Munster et al. [65]. In this study, patients (44 years old or younger) were treated with $\mathrm{AC}-\mathrm{T}$ or FEC \pm triptorelin. After 49 patients were enrolled, the accrual was halted early due to futility. However, in the control group the rates of CRA, CRM and ReMen were 24\%, $10 \%$ and $90 \%$, respectively (median follow-up of 18 months from completion of CT). The differences in terms of ovarian toxicity showed in these trials may be explained by the prevalence of younger patients, the cumulative dose of alkylating agents delivered and the use of tamoxifen, but also by the different definition of amenorrhea, stratification criteria and duration of the follow-up period [66].

\subsubsection{Endocrine treatment}

Tamoxifen is the cornerstone of endocrine treatment of premenopausal patients affected by endocrine-responsive EBC. Premenopausal women receiving tamoxifen showed a reduced probability to have monthly bleeding within one year after chemotherapy [79]. In large prospective trials, the use of this drug has been significantly associated with an increased rate and/or duration of CRA [39,42,43,66-69]. In one of these studies, the effect of adjuvant tamoxifen on CRA appeared to be limited to women $>40$ years of age [68]. Adjuvant tamoxifen following CT for EBC appeared to result in a slightly, but statistically significant, increase in the risk of CRM [3]. Still, how tamoxifen influences ovarian toxicity remains unclear. The suggested mechanisms of interference include the alteration of the hypothalamic-ovarian feedback loop regulating estrogen synthesis and higher plasma estradiol levels, due to the selective estrogen receptor modulation induced by tamoxifen $[35,70]$.

\subsubsection{Genetic factors}

It has been proposed that specific genes have a role not only in determining the age of natural menopause [71] but also in CRA/CRM [28]. In a prospective study on a cohort of 127 young $\mathrm{BC}$ survivors, a common variant of a cyclophosphamide metabolizing enzyme (CYP3A $4 * 1 \mathrm{~B})$ was found to be associated with higher risk of ovarian failure after cyclophosphamide-based chemotherapy compared with the wild-type genotype [72]. These data show that genetic markers, other than age and characteristics of CT-regimens, may have a role in predicting ovarian toxicity induced by CT. Further prospective correlative trials will clarify the clinical impact of these new predictive biomarkers of toxicity.

\section{The prognostic significance of CRA, CRM and RM in patients with $\mathbf{E B C}$}

A positive influence of CRA and CRM on the survival of patients affected by EBC has been reported in the majority of studies [12]. The mechanisms underlying the benefits of chemotherapy in endocrine-responsive EBC patients, however, remain uncertain. Clinical evidence suggests that $\mathrm{CT}$ may exert a dual mechanism: direct cytotoxic activity and an indirect suppressive hormonal effect mediated by damage to ovarian estrogen-producing cells $[12,32]$. This may explain the clinical evidence that chemotherapy is more effective in younger, rather than in older, patients.

In the largest prospective trial evaluating amenorrhea as a consequence of adjuvant CT-regimens (AT/ACT/AC-T) in premenopausal EBC patients, it was initially shown that patients with CRA (defined as lack of menstruation for $>6$ months during 24 months of follow-up) had significantly better overall and disease-free survival than those without amenorrhea, regardless of treatment received and estrogenreceptor status $[13,43]$. In a subsequent 12-month landmark analysis, the clinical significance of CRA was found to be restricted to patients with ER + disease [73]. These data are consistent with results from IBCSG Trial 13-93 and IBCSG Trial VIII, where ovarian function suppression obtained by CT (CRA) was associated with improved outcome only in the subgroup of patients with $\mathrm{ER}+\mathrm{BC}[74,75]$.

Whether prolonged duration of transient CRA results in survival advantages is uncertain. In some studies, patients treated with anthracyclines/CMF showed an improved survival benefit if they experienced amenorrhea, irrespective of the time of onset and duration [76,77]. In another study, women who received $\mathrm{CMF} / \mathrm{CEF}$ showed a better survival rate if they had achieved amenorrhea at 12 months, but not at 6 months [78]. Interestingly, in a recent retrospective analysis on 872 premenopausal patients (median age at diagnosis: 41 years, range, 21-54) who received various CT-regimens for stage I-III BC, RM was significantly associated with shorter DFS (not OS) in both hormone receptor-positive and -negative patients at multivariate analysis [87]. These results suggest that ReMen, more adequately than CRA, might reflect the endocrine-mediated anticancer effect of chemotherapy, at least in patients $>35$ years [79].

\section{Preserving fertility in breast cancer patients}

Infertility is among the major consequences of POF induced by CT [15]. Issues related to residual fertility following exposure to CT-regimens are of mounting importance due to the rising tendency by an increasing proportion of women to delay pregnancy to later in life [15]. It has been reported that more than $50 \%$ of young women have fertility concerns upon being diagnosed with $\mathrm{BC}$, and CT-induced infertility may influence treatment decisions in almost $30 \%$ of younger BC patients [80]. Moreover, whether subsequent pregnancy could increase the risk of recurrence remains a great concern in BC survivors, particularly in those with endocrine-responsive disease. This is despite a number of observational studies that showed no detrimental effects from pregnancy after BC $[13,42,73,78]$. 
A number of effective methods are available for younger $\mathrm{BC}$ patients wishing to preserve their fertility potential from damage of CT, including cryopreservation techniques and/or the administration of GnRH-agonists [15,44]. However, each of these methods presents various pros and contras. Methods based on cryopreservation are costly, complex, and have a significant failure rate $[81,82]$. Both embryo and oocyte preservation techniques require ovarian stimulation before harvest. This exposes patients to high estrogen levels, a potential risk in patients with $\mathrm{ER}+\mathrm{BC}$. In addition, laparoscopy and general anesthesia are required, inducing a delay of 2-6 weeks in starting CT. Importantly, the efficacy of these treatments in patients $>40$ years of age seems to be uncertain [83].

The use of GnRH analogs has some advantages. The treatment is simple to administer, is low in cost, and CT need not be delayed. Moreover, a male partner is not required.

However, GnRH agonists must be administered one week to six months before $\mathrm{CT}$ and continue until the end of CT. Also the safety of the use of GnRH agonists in cancer patients has been questioned. Since GnRH receptors are expressed by a variety of cancers and mediate several effects (e.g., inhibition of proliferation, induction of cell-cycle arrest, and inhibition of apoptosis), it has been suggested that the concomitant administration of $\mathrm{GnRH}$ agonist therapy might antagonize CT, reducing its efficacy $[84,85]$. Therefore, ovarian suppression with GnRH agonists might be safer in women with estrogen receptor-negative BC [86]. Detrimental effects of GnRH agonists on patients under CT, however, were not shown in clinical trials.

Moreover, results from clinical trials evaluating the efficacy of GnRH agonists in preventing CT-induced ovarian toxicity are conflicting. A recent meta-analysis including six randomized trials that evaluated ovarian function after cotreatment with a GnRH agonist and various CT-regimens concluded that this approach may be beneficial for protection of menstrual function [87]. However, the treatment with a GnRH agonist combined with CT was not associated with a statistically significant difference in the rate of spontaneous pregnancy following CT. Limitations of these findings included the small size of most of the trials evaluated, the lack of adequate analyzable data, the generally short period of follow-up, methodological weakness of one of the trials, and the use of different treatment protocols [87].

More recent studies have not clarified the issue. The positive role of $\mathrm{GnRH}$ agonists in preserving ovarian function during chemotherapy for EBC patients is supported by two trials, the Italian PROMISE-GIM6 trial [63], and a trial from the Royal Marsden Hospital, UK [88]. Similar results were obtained by Badawy et al. [89] in a smaller study. Conversely, other smaller trials failed to demonstrate any benefit of the GnRH agonists in preserving fertility in patients with EBC, including the Zoladex Rescue of Ovarian Function (ZORO) trial [64], the Ovarian Protection Trial in Estrogen Negative (OPTION) [90] and the study by Munster et al. [65]. Results from ongoing studies aimed at evaluating the role of ovarian suppression in patients affected by EBC under CT (for example, the Prevention of Early Menopause Study POEMS; South West Oncology Group-SWOG study 0230) are awaited.

Finally, it has been suggested that the concomitant use of GnRH agonists for ovarian suppression and cryopreservation increases the chances of preserving fertility in young women $[44,88]$.

According to an update of American Society of Clinical Oncology practical guidelines on fertility preservation in cancer patients, sperm and embryo cryopreservation, as well as oocyte cryopreservation, are considered standard practice. Other fertility preservation methods should be considered investigational and should be performed by providers with the necessary expertise [91].

\section{Measuring ovarian reserve in healthy women and in those with cancer}

Ovarian reserve (OR) indicates the number and quality of follicles that, at any given age, are available to produce a dominant follicle late in the follicular phase of the menstrual cycle. Several causes impair OR, including ovarian surgery, exposure to viral or environmental toxic agents such as smoking, with anticancer CT or radiotherapy being the most common cause of acquired loss of OR [24]. However, OR may be reduced in cancer patients at diagnosis [24]. Similarly, ovarian response of patients who undergo controlled ovarian hyperstimulation before $\mathrm{CT}$ is diminished even before treatment [92]. In a large cohort of 40-year-old women not undergoing systemic treatment, an unusual earlier median age of menopause onset was found [93-95]. Conversely, other authors did not find any impact of BC on OR [96]. Therefore, the real impact of cancer (particularly of solid malignancies) on OR, and the potential mechanisms of impairment of ovarian function induced by cancer itself remain to be clarified.

In the fertility and assisted reproduction setting, OR is measured by a number of procedures, such as ultrasound evaluation of the antral follicle count (AFC) and assessment of serum levels of FSH, estradiol, inhibin-B and anti-Müllerian hormone (AMH) [97]. AMH is emerging as the most promising measure of OR. It is produced by the small growing follicles and exerts a paracrine effect on the primordial follicle. AMH inhibits the recruitment of primordial follicles into the growing follicle pool by reducing sensitivity to FSH. Conversely, inhibin-B positively influences folliculogenesis in the ovary (Fig. 1) [98]. AMH serum levels in normal cycling women decline with age and become undetectable in menopausal women [99]. In several studies, AMH accurately reflects the ovarian follicle reserve and represents the most sensitive marker for the age-related decline in the number of primordial follicles. In addition, AMH and AFC offer the most reliable assessment of the reproductive lifespan of the ovaries, as well as of the risk of premature ovarian 


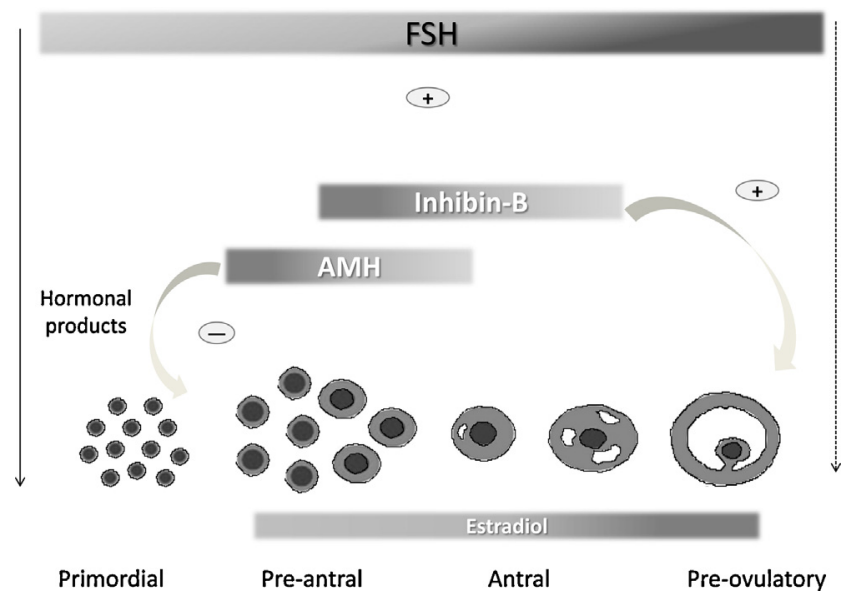

Fig. 1. Changing patterns of hormone production by ovarian follicles from resting to pre-ovulatory stages (darker shading in hormone labels corresponds to greater hormone production). Legend: The rise in FSH serum levels at the end of a previous menstrual cycle drives the initial follicle recruitment. Growing follicles produce estradiol and other peptide hormones, such as $\mathrm{AMH}$ and inhibin-B, which are important in feedback regulation of FSH. $\mathrm{AMH}$ is secreted by pre-antral and antral follicles and appeared to play an inhibiting role in initial recruitment of primary follicles from the resting primordial follicle pool and in the selection of the dominant follicle, by reducing the sensitivity of antral follicles for FSH. Inhibin-B may have paracrine functions positively influencing folliculogenesis.

failure. Moreover, they are the best predictors of the success of in vitro fertilization cycles [97].

In women treated with chemotherapy for Hodgkin's lymphoma, and in young women who received chemotherapy/radiotherapy for childhood cancer, [100-102] AMH was the most sensitive predictor of OR, compared with FSH and inhibin-B.

A limited number of studies evaluated $\mathrm{OR}$ in patients affected by EBC receiving adjuvant CT/ET. Basal measurements of AMH, FSH, inhibin-B, estrogen levels and AFC have been found to be sensitive predictors of OR in patients with EBC undergoing CT $[33,35,103]$. Women still menstruating after the end of CT present, however, higher FSH levels, lower AMH and inhibin-B levels, as well as lower AFC, compared to controls [35,103]. Lower levels of AMH were strictly related to a low AFC, thus predicting a reduced likelihood of future pregnancy [35]. High pretreatment levels of AMH were associated with high levels of AMH one year after completing treatment [104]. Furthermore, patients with pretreatment levels of AMH above the median of the study group showed more favorable post-treatment ovarian function, including those with EBC [104].

AMH levels decrease after the first courses of chemotherapy and progressively thereafter during treatment [34,104]. In a cohort of 50 premenopausal women with EBC, it was demonstrated that $\mathrm{CT}$ induced rapid decreases in $\mathrm{AMH}$, inhibin-B, and AFC, without modifying estradiol levels [33]. Moreover, AMH levels prior to chemotherapy were lower in women who became amenorrheic within 6 months, compared to those who resumed menses. No significant difference in pretreatment inhibin-B levels was found between groups [33]. On the other hand, it has been observed that prechemotherapy inhibin-B and AMH were lower in women with EBC who experienced CRA, both predicting CRA [105]. Likewise, in a cohort of 127 women who received adjuvant $\mathrm{CT}$ for EBC, AMH and inhibin-B were significantly associated with the risk of CRA, compared with age-matched controls [102]. AMH was significantly lower and FSH significantly higher in menstruating women who developed subsequent CRA [106]. Conflicting results have been reported regarding the influence of tamoxifen on AMH and inhibin-B $[33,35,106]$.

\section{When are patients with chemotherapy-related amenorrhea actually menopausal?}

In healthy women, a few well defined clinical aspects (age, menstrual history and menopausal symptoms) are generally indicative of menopausal status. Nevertheless, natural menopause can only be retrospectively established after 12 consecutive months of spontaneous amenorrhea, with biochemical confirmation of FSH and estradiol serum levels within the menopausal range.

In studies assessing ovarian function following $\mathrm{CT}$, the definition of menopause is heterogeneous [107]. In most of these reports, the cessation of menses was the only surrogate marker of menopause, although the follow-up period was limited. According to the National Cancer Comprehensive Network (NCCN) the diagnosis of menopause in $\mathrm{BC}$ patients should include any of the following criteria: prior bilateral oophorectomy; age older than 60 years; age younger than 60 years and amenorrhea for $\geq 12$ months in the absence of chemotherapy, tamoxifen, toremifene, or ovarian suppression and FSH and estradiol in the postmenopausal range. If the patient is taking tamoxifen or toremifene, and is under 60, then FSH and plasma estradiol levels should be in postmenopausal ranges [10]. In these guidelines, it was emphasized that for premenopausal women starting adjuvant ET, CRA is not a reliable indicator of menopausal status, as ovarian function may still be intact or resume despite chemotherapy-induced anovulation/amenorrhea. If treatment with $\mathrm{AI}$ is foreseen, serial measurements of FSH/estradiol are recommended in patients with CRA [10]. However, these factors are not completely reliable to confirm menopause in these patients [108].

In particular, biochemical tests present a number of limits. Elevated FSH and reduced estradiol levels generally confirm the clinical diagnosis of menopause. The duration of transition toward menopause, however, is highly variable, as it is a dynamic continuum, with FSH/estradiol values subject to wide fluctuation. Therefore, a diagnostic cut-off for these biomarkers is difficult to define. Additionally, testing for FSH/estradiol only at single points in time is not sufficient to confirm menopause. In this respect, serial assessments of these biomarkers would be more reliable, but the number and 
intervals of time points of assessment remain arbitrary. Moreover, when CT is used, the prevision of the definitive loss of ovarian function may be more erratic. In addition, some technical aspects may negatively affect reliability of biochemical tests. Current plasma estradiol radioimmunoassay is not sufficiently sensitive to detect the low postmenopause estradiol levels [109]. Tandem mass spectrometry, a validated method dosing steroids in the $\mathrm{pg} / \mathrm{ml}$ range, may not be widely available [18]. Furthermore, tamoxifen has been reported to increase circulating estrogens and decrease FSH levels [110]. Increased levels of estradiol may result from cross-reactivity of tamoxifen and its metabolites in the estradiol assay. Likewise, exemestane, a steroidal AI, may interfere with serum estradiol measurement [111]. AI provoke a strong decrease in estrogen levels and increase FSH levels in postmenopausal patients [110]. In premenopause, though, the inhibition of estrogen production is only temporary and the subsequent FSH increase may, in turn, stimulate follicular growth, aromatase production and restore pre-CT estradiol levels [17].

Interestingly, AMH and inhibin-B have shown a potential predictive role of ovarian function recovery in studies evaluating OR in limited cohorts of cancer patients, including those with BC. AMH levels, in particular, appear to provide a practical tool useful in defining the individual risk of POF induced by CT [104]. Conversely, in a retrospective study on a very young population of women who received CT/ET for EBC (median age 37 years, range 27-40), compared with age-matched controls, neither the baseline nor changing levels in AMH appeared to be predictive markers for subsequent menstrual status following CT [112].

Unfortunately, due to some limitations in these studies, it is not possible to define the role of these new markers of OR as predictive factors of CRM, especially in BC patients. In fact, none of these studies has been specifically designed to test $\mathrm{AMH} /$ inhibin-B as predictive factors of CRM; cohorts of patients are limited, the age distribution among the cohorts appears inhomogeneous, as does the treatment received, the duration of follow-up and the sample collection time.

Very recently, in a prospective study with a 5-year median follow-up, basal serum AMH was reported to be strongly predictive of long-term ovarian function in a cohort of patients undergoing CT $( \pm \mathrm{ET})$ for EBC [113]. In particular, AMH remained the only significant predictive factor of OR in a multivariate analysis including age and FSH.

\section{Ovarian reserve markers and the choice of endocrine therapy in EBC patients}

In clinical practice, ascertaining residual ovarian activity in a premenopausal patient with endocrine-responsive EBC and CRA is of key importance not only to define the fertility potential following completion of CT, but also to select the appropriate adjuvant ET (tamoxifen versus AI) [114]. To this aim, AMH may be used as suggested in Fig. 2.

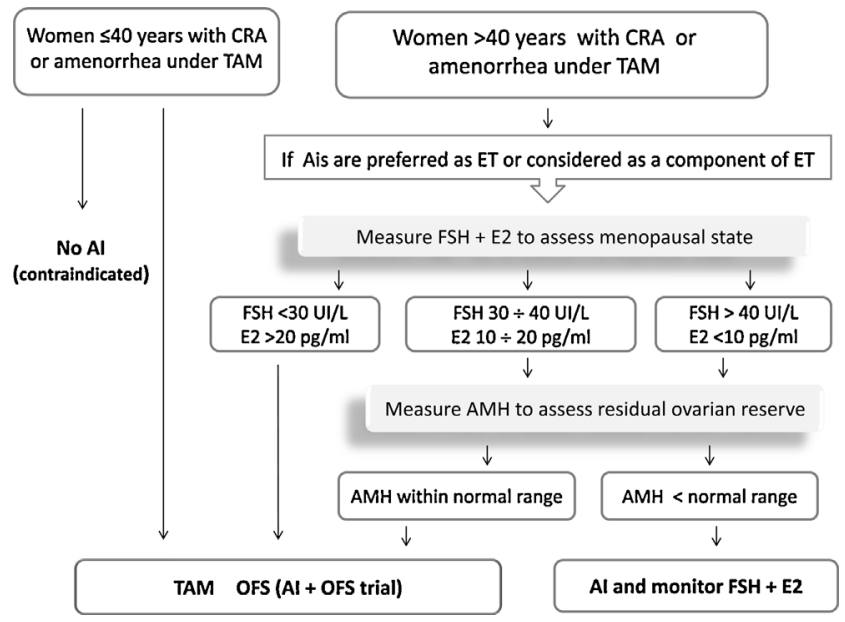

Fig. 2. Practical approaches suggested when aromatase inhibitors are the preferred endocrine strategy for patients with endocrine-responsive EBC and CRA or amenorrhea under tamoxifen. Abbreviations: AI, aromatase inhibitor; AMH, anti-Müllerian hormone; CRA, chemotherapy induced amenorrhea; E2, estradiol; EBC, early breast cancer; ET, endocrine therapy; FSH, follicle-stimulating hormone; OFS, ovarian function suppression (oophorectomy or chemical suppression with a gonadotropin-releasing hormone agonist); TAM, tamoxifen

Women under the age of 40 generally maintain residual OR following CT, despite persistent CRA, and, therefore, they should not receive an AI as the only adjuvant ET. If estrogen depletion is the desired endocrine strategy, this should include ovarian function suppression (OFS; oophorectomy or chemical suppression with a gonadotropin-releasing hormone agonist) in combination with tamoxifen $[9,10]$. Alternatively, entering a clinical trial is an advisable option.

Women over the age of 40 who have developed CRA or amenorrhea during tamoxifen should measure FSH and estradiol, preferably with a high-quality estradiol assay (i.e., mass spectrometry), which allows a high sensitivity (in the order of $\mathrm{pg} / \mathrm{ml}$ ) together with a high-specificity (no cross reaction with other steroidal molecules) [115]. Women with levels within the premenopausal range (i.e., $\mathrm{FSH}<30 \mathrm{UI} / \mathrm{L}$ and estradiol $>20 \mathrm{pmol} / \mathrm{L}$ ), should receive tamoxifen alone or tamoxifen + OFS.

If intermediate hormone levels (FSH: $30-40 \mathrm{UI} / \mathrm{L}$ and estradiol:10-20 pg/ml) appear to be indicative of menopausal transition/perimenopause, measuring AMH levels may be useful in detecting residual ovarian activity [113]. If FSH/estradiol levels are consistent with menopause $(\mathrm{FSH}>40 \mathrm{UI} / \mathrm{L}$ and estradiol $<10 \mathrm{pmol} / \mathrm{L})$, AI may be prescribed. However, basal and serial hormone monitoring should be performed (e.g., every 4 months), and AMH levels should be prudentially measured even in this group.

Since CRA may be a reversible condition especially in younger women, patients under $\mathrm{AI}$ who experience the occurrence of certain symptoms, such as the onset of vaginal bleeding or the sudden cessation of hot flashes, should be rapidly referred to the clinician [18]. Similarly, sexually active women with CRA need to be counseled for the 
maintenance of birth control, given that they may ovulate and, therefore, become pregnant, despite the absence of menses.

\section{Conclusions}

Ovarian toxicity is a major concern of young cancer patients who need CT for a cure. The reduction in fertility potential induced by CT-regimens should be taken into consideration in family planning decisions throughout diagnosis and follow-up, and effective approaches aimed at preserving ovarian function should be regularly offered to women who need to receive CT and ET $[5,34,63,91,116]$. However, since cryopreservation of embryos or oocytes requires controlled ovarian stimulation, the risk of increased peak estradiol levels with this strategy in patients with endocrine-responsive EBC should be discussed before the procedure. The controlled ovarian stimulation using tamoxifen or letrozole in conjunction with gonadotropin may be safer for women with endocrine-responsive BC [116].

Evaluation of OR in cancer patients may be challenging, and, therefore, availability of predictors providing more reliable assessments of ovarian function is of major clinical importance. At present, AFC, AMH and inhibin-B are reliable predictive factors of fertility, even in cancer patients. Ongoing large prospective trials will define which values of the available parameters assessing OR are indicative of irreversible loss of ovarian function (i.e., the true menopausal status) in women with endocrine-responsive EBC and CRA. However, in a multidisciplinary evaluation with endocrinologists, a careful use of AMH values may improve the assessment of residual OR and, therefore, of CRM, particularly in a specific subset of women, such as those with endocrine-responsive EBC, CRA and uncertain values of FSH/estradiol.

Further investigations aimed at establishing the effects on ovarian function of newer cytotoxic regimens would offer effective alternative treatments with less ovarian toxicity. A deeper knowledge of potential mechanisms sustaining ovarian toxicity triggered by specific drugs remains the rational approach to select the most suitable strategy to prevent ovarian toxicity.

\section{Conflict of interest}

The authors declare that there is no conflict of interest that could be perceived as prejudicing the impartiality of the research reported.

\section{Funding}

No funds were requested from any pharmaceutical firms or other industries/institutions. Valentina Sini is financed through the $\mathrm{PhD}$ University Grant program "Clinical and Experimental Research Methodologies in Oncology" provided by the Faculty of Medicine and Psychology, "Sapienza" University of Rome.

\section{Reviewers}

Dr. PierFranco Conte, Director, University Hospital, Modena, Department of Oncology and Hematology, Via Del Pozzo, 71, I-41100 Modena, Italy.

Dr. Lucia Del Mastro, UO Sviluppo Terapie Innovative, Oncologia Medica A, IRCCS AOU San Martino-IST, Istituto Nazionale per la Ricerca, sul Cancro, L.go R. Benzi 10, I16132 Genova, Italy.

Dr. Giampaolo Papi, Department of Internal Medicine, Section of Endocrinology, University of Modena and Reggio Emilia, Modena, Italy.

\section{References}

[1] American Cancer Society, Breast Cancer Facts \& Figures, 2011-2012 www.cancer.org/Research/CancerFactsFigures/ACSPC-031941

[2] Siegel R, Naishadham D, Jemal A. Cancer statistics, 2012. CA: A Cancer Journal for Clinicians 2012;62:10-29.

[3] Bines J, Oleske D, Cobleigh M. Ovarian function in premenopausal women treated with adjuvant chemotherapy for breast cancer. Journal of Clinical Oncology 1996;14:1718-29.

[4] Samphao S, Wheeler AJ, Rafferty E, et al. Diagnosis of breast cancer in women age 40 and younger: delays in diagnosis result from underuse of genetic testing and breast imaging. American Journal of Surgery 2009;198:538-43.

[5] Cardoso F, Loibl S, Pagani O, et al. European Society of Breast Cancer Specialists. The European Society of Breast Cancer Specialists recommendations for the management of young women with breast cancer. European Journal of Cancer 2012;48:3355-77.

[6] Fredholm H, Eaker S, Frisell J, Holmberg L, Fredriksson I, Lindman $\mathrm{H}$. Breast cancer in young women: poor survival despite intensive treatment. PLoS ONE 2009;4:e7695.

[7] Swanson GM, Lin CS. Survival patterns among younger women with breast cancer: the effects of age, race, stage, and treatment. Journal of the National Cancer Institute Monographs 1994;16:69-77.

[8] Colleoni M, Rotmensz N, Robertson C, et al. Very young women ( $<35$ years) with operable breast cancer: features of disease at presentation. Annals of Oncology 2002;13:273-9.

[9] Goldhirsch A, Wood WC, Coates AS, et al. Strategies for subtypesdealing with the diversity of breast cancer: highlights of the St Gallen International Expert Consensus on the Primary Therapy of Early Breast Cancer 2011. Annals of Oncology 2011;22:1736-47.

[10] National Comprehensive Cancer Network - Breast Cancer Guidelines; 2013. www.nccn.org (accessed February 2013).

[11] Early Breast Cancer Trialists' Collaborative Group. Effects of chemotherapy and hormonal therapy for early breast cancer on recurrence and 15-year survival: an overview of the randomised trials. Lancet 2005;365:1687-717

[12] Walshe J, Denduluri N, Swain S. Amenorrhea in pre-menopausal women after adjuvant chemotherapy for breast cancer. Journal of Clinical Oncology 2006;24:5769-79.

[13] Swain SM, Jeong JH, Geyer Jr CE, et al. Longer therapy, iatrogenic amenorrhea, and survival in early breast cancer. New England Journal of Medicine 2010;362:2053-65.

[14] Schover LR. Premature ovarian failure and its consequences: vasomotor symptoms, sexuality, and fertility. Journal of Clinical Oncology 2008;26:753-8. 
[15] Ruddy KJ, Partridge AH. Fertility (male and female) and menopause. Journal of Clinical Oncology 2012;30:3705-11.

[16] Burstein HJ, Prestrud AA, Seidenfeld J, et al. American Society of Clinical Oncology clinical practice guideline: update on adjuvant endocrine therapy for women with hormone receptor-positive breast cancer. Journal of Clinical Oncology 2010;28:3784-96.

[17] de Ziegler D, Mattenberger C, Luyet C, Romoscanu I, Irion NF, Bianchi-Demicheli F. Clinical use of aromatase inhibitors (AI) in premenopausal women. Journal of Steroid Biochemistry and Molecular Biology 2005;95:121-7.

[18] Smith IE, Dowsett M, Yap YS, et al. Adjuvant aromatase inhibitors for early breast cancer after chemotherapy-induced amenorrhea: caution and suggested guidelines. Journal of Clinical Oncology 2006;24:2444-7.

[19] Ortmann O, Pagani O, Jones A, et al. Which factors should be taken into account in perimenopausal women with early breast cancer who may become eligible for an aromatase inhibitor? Recommendations of an expert panel. Cancer Treatment Reviews 2011;37:97-104.

[20] Henry NL, Banerjee M, Hayden J, et al. Predictors of Recovery of Ovarian Function during Aromatase Inhibitor (AI) Therapy. Cancer Research 2011;71(Suppl. 3) [abstract PD04-01].

[21] Faddy MJ, Gosden RG, Gougeon A, Richardson SJ, Nelson JF. Accelerated disappearance of ovarian follicles in mid-life: implications for forecasting menopause. Human Reproduction (Oxford, England) 1992;10:1342-6.

[22] Gougeon A, Ecochard R, Thalabard JC. Age-related changes of the population of human ovarian follicles: increase in the disappearance rate of non-growing and early-growing follicles in aging women. Biology of Reproduction 1994;50:653-63.

[23] Coulam CB, Adamson SC, Annegers JF. Incidence of premature ovarian failure. Obstetrics and Gynecology 1986;67:604.

[24] De Vos M, Devroey P, Fauser BCJM. Primary ovarian insufficiency. Lancet 2010;376:911-21.

[25] Chapman R. Effect of cytotoxic therapy on sexuality and gonadal function. Seminars in Oncology 1982;9:84-94.

[26] Sonmezer M, Oktay K. Fertility preservation in young women undergoing breast cancer therapy. Oncologist 2006;11:422-34.

[27] Meirow D, Biederman H, Anderson RA, Wallace WH. Toxicity of chemotherapy and radiation on female reproduction. Clinical Obstetrics and Gynecology 2010;53:727-9.

[28] Meirow D. Reproduction post-chemotherapy in young cancer patients. Molecular and Cellular Endocrinology 2000;169 (November): $123-31$

[29] Morgan S, Anderson RA, Gourley C, Wallace WH, Spears N. How do chemotherapeutic agents damage the ovary? Human Reproduction Update 2012;18:525-35.

[30] Ben-Aharon I, Shalgi R. What lies behind chemotherapy-induced ovarian toxicity? Reproduction 2012;144:153-63.

[31] Ben-Aharon I, Meizner I, Granot T, et al. Chemotherapy-induced ovarian failure as a prototype for acute vascular toxicity. Oncologist 2012;17:1386-93.

[32] Partridge AH, Ruddy KJ. Fertility and adjuvant treatment in young women with breast cancer. Breast 2007;16(Suppl. 2): $175-81$.

[33] Anderson RA, Themmen AP, Al-Qahtani A, Groome NP, Cameron DA. The effects of chemotherapy and long-term gonadotrophin suppression on the ovarian reserve in premenopausal women with breast cancer. Human Reproduction 2006;21:2583-92.

[34] Oktay K, Oktem O, Reh A, Vahdat L. Measuring the impact of chemotherapy on fertility in women with breast cancer. Journal of Clinical Oncology 2006;24:4044-6.

[35] Partridge AH, Ruddy KJ, Gelber S, et al. Ovarian reserve in women who remain premenopausal after chemotherapy for early stage breast cancer. Fertility and Sterility 2010;94:638-44.

[36] Ganz PA, Greendale GA, Petersen L, Kahn B, Bower JE. Breast cancer in younger women: reproductive and late health effects of treatment. Journal of Clinical Oncology 2003;21:4184-93.
[37] Stearns V, Schneider B, Henry NL, Hayes DF, Flockhart DA. Breast cancer treatment and ovarian failure: risk factors and emerging genetic determinants. Nature Reviews Cancer 2006;6:886-93.

[38] Jeruss JS, Woodruff TK. Preservation of fertility in patients with cancer. New England Journal of Medicine 2009;360:902-11.

[39] Goodwin PJ, Ennis M, Pritchard KI, Trudeau M, Hood N. Risk of menopause during the first year after breast cancer diagnosis. Journal of Clinical Oncology 1999;17:2365-70.

[40] Padmanabhan N, Howell A, Rubens RD. Mechanism of action of adjuvant chemotherapy in early breast cancer. Lancet 1986;23:411-4.

[41] Del Mastro L, Venturini M, Sertoli MR, Rosso R. Amenorrhea induced by adjuvant chemotherapy in early breast cancer patients: prognostic role and clinical implications. Breast Cancer Research and Treatment 1997;43:183-90.

[42] Pagani O, O'Neill A, Castiglione M, et al. Prognostic impact of amenorrhoea after adjuvant chemotherapy in premenopausal breast cancer patients with axillary node involvement: results of the International Breast Cancer Study Group (IBCSG) Trial VI. European Journal of Cancer 1998;34:632-40.

[43] Swain SM, Land SR, Ritter MW, et al. Amenorrhea in premenopausal women on the doxorubicin-and-cyclophosphamide followed bydocetaxel arm of NSABP B-30 trial. Breast Cancer Research and Treatment 2009;113:315-20.

[44] Del Mastro L, Giraudi S, Levaggi A, Pronzato P. Medical approaches to preservation of fertility in female cancer patients. Expert Opinion on Pharmacotherapy 2011;12:387-96.

[45] Tham YL, Sexton K, Weiss H, Elledge R, Friedman LC, Kramer R. The rates of chemotherapy induced amenorrhea in patients treated with adjuvant doxorubicin and cyclophosphamide followed by a taxane. American Journal of Clinical Oncology 2007;30:126-32.

[46] Han HS, Ro J, Lee KS, et al. Analysis of chemotherapy-induced amenorrhea rates by three different anthracycline and taxane containing regimens for early breast cancer. Breast Cancer Research and Treatment 2009;115:335-42.

[47] Martin M, Pienkowski T, Mackey J, et al. Adjuvant docetaxel for node-positive breast cancer. New England Journal of Medicine 2005;352:2302-13.

[48] Najafi S, Djavid GE, Mehrdad N, et al. Taxane-based regimens as a risk factor for chemotherapy-induced amenorrhea. Menopause 2011;18:208-12.

[49] Fornier MN, Modi S, Panageas KS, Norton L, Hudis C. Incidence of chemotherapy-induced, long-term amenorrhea in patients with breast carcinoma age 40 years and younger after adjuvant anthracycline and taxane. Cancer 2005;104:1575-9.

[50] Zhou WB, Yin H, Liu XA, et al. Incidence of chemotherapy-induced amenorrhea associated with epirubicin, docetaxel and navelbine in younger breast cancer patients. BMC Cancer 2010;10:281 .

[51] Berliere M, Dalenc F, Malingret N, et al. Incidence of reversibile amenorrea in women with breast cancer undergoing adjuvant anthracycline-based chemotherapy with or without docetaxel. BMC Cancer 2008;8:56.

[52] Lee S, Kil WJ, Chun M, et al. Chemotherapy-related amenorrhea in premenopausal women with breast cancer. Menopause 2009;16:98-103.

[53] Pérez-Fidalgo JA, Roselló S, García-Garré E, et al. Incidence of chemotherapy-induced amenorrhea in hormone-sensitive breast cancer patients: the impact of addition of taxanes to anthracyclinebased regimens. Breast Cancer Research and Treatment 2010;120: 245-51.

[54] Okanami Y, Ito Y, Watanabe C, et al. Incidence of chemotherapyinduced amenorrhea in premenopausal patients with breast cancer following adjuvant anthracycline and taxane. Breast Cancer 2011;18:182-8.

[55] Ganz PA, Land SR, Geyer Jr CE, et al. Menstrual history and qualityof-life outcomes in women with node-positive breast cancer treated with adjuvant therapy on the NSABP B-30 trial. Journal of Clinical Oncology 2011;29:1110-7. 
[56] Goldhirsch A, Gelber RD, Castiglione M. The magnitude of endocrine effects of adjuvant chemotherapy for premenopausal breast cancer patients. The International Breast Cancer Study Group. Annals of Oncology 1990;1:183-8.

[57] Basser RL, O’Neill A, Martinelli G, et al. Multicycle dose-intensive chemotherapy for women with high-risk primary breast cancer: results of International Breast Cancer Study Group Trial 15-95. Journal of Clinical Oncology 2006;24:370-8.

[58] Venturini M, Del Mastro L, Aitini E, et al. Dose-dense adjuvant chemotherapy in early breast cancer patients: results from a randomized trial. Journal of the National Cancer Institute 2005;97:1724-33.

[59] Abusief ME, Missmer SA, Ginsburg ES, Weeks JC, Partridge AH. The effects of paclitaxel, dose density, and trastuzumab on treatmentrelated amenorrhea in premenopausal women with breast cancer. Cancer 2010;116:791-8.

[60] Di Cosimo S, Alimonti A, Ferretti G, et al. Incidence of chemotherapy-induced amenorrhea depending on the timing of treatment by menstrual cycle phase in women with early breast cancer. Annals of Oncology 2004;15:1065-71.

[61] Petrek JA, Naughton MJ, Case LD, et al. Incidence, time course, and determinants of menstrual bleeding after breast cancer treatment: a prospective study. Journal of Clinical Oncology 2006;24:1045-51.

[62] Sukumvanich P, Case LD, Van Zee K, et al. Incidence and time course of bleeding after long-term amenorrhea after breast cancer treatment: a prospective study. Cancer 2010;116:3102-11.

[63] Del Mastro L, Boni L, Michelotti A, et al. Effect of the gonadotropinreleasing hormone analogue triptorelin on the occurrence of chemotherapy-induced early menopause in premenopausal women with breast cancer: a randomized trial. Journal of the American Medical Association 2011;306:269-76.

[64] Gerber B, von Minckwitz G, Stehle H, et al. Effect of luteinizing hormone-releasing hormone agonist on ovarian function after modern adjuvant breast cancer chemotherapy: the GBG 37 ZORO study. Journal of Clinical Oncology 2011;29:2334-41.

[65] Munster PN, Moore AP, Ismail-Khan R, et al. Randomized trial using gonadotropin-releasing hormone agonist triptorelin for the preservation of ovarian function during (neo)adjuvant chemotherapy for breast cancer. Journal of Clinical Oncology 2012;30:533-8.

[66] Partridge AH. Ovarian suppression for prevention of premature menopause and infertility: empty promise or effective therapy? Journal of Clinical Oncology 2012;30:479-81.

[67] Boccardo F, Rubagotti A, Bruzzi P, et al. Chemotherapy versus tamoxifen versus chemotherapy plus tamoxifen in node-positive, estrogen receptor-positive breast cancer patients: results of a multicentric Italian study. Breast Cancer Adjuvant Chemo-Hormone Therapy Cooperative Group. Journal of Clinical Oncology 1990;8:1310-20.

[68] Jordan VC, Fritz NF, Langan-Fahey S, Thompson M, Tormey DC. Alteration of endocrine parameters in premenopausal women with breast cancer during long-term adjuvant therapy with tamoxifen as the single agent. Journal of the National Cancer Institute 1991;83:1488-91.

[69] Colleoni M, Gelber S, Goldhirsch A, et al. Tamoxifen after adjuvant chemotherapy for premenopausal women with lymph node-positive breast cancer: International Breast Cancer Study Group Trial 13-93. Journal of Clinical Oncology 2006;24:1332-41.

[70] Jung M, Shin HJ, Rha SY, et al. The clinical outcome of chemotherapy-induced amenorrhea in premenopausal young patients with breast cancer with long-term follow-up. Annals of Surgical Oncology 2010;17:3259-68.

[71] Rose D, Davis T. Effects of adjuvant chemohormonal therapy on the ovarian and adrenal function of breast cancer patients. Cancer Research 1980;40:4043-7.

[72] Stolk L, Zhai G, van Meurs JB, et al. Loci at chromosomes 13, 19 and 20 influence age at natural menopause. Nature Genetics 2009;41:645-7.

[73] Su HI, Sammel MD, Velders L, et al. Association of cyclophosphamide drug-metabolizing enzyme polymorphisms and chemotherapy-related ovarian failure in breast cancer survivors. Fertility and Sterility 2010;94:645-54.

[74] Swain SM, Jeong JH, Wolmark N. Amenorrhea from breast cancer therapy-not a matter of dose. New England Journal of Medicine 2010;363:2268-70.

[75] International Breast Cancer Study Group. Tamoxifen after adjuvant chemotherapy for premenopausal women with lymph node-positive breast cancer: International Breast Cancer Study Group Trial 13-93. Journal of Clinical Oncology 2006;24:1332-41.

[76] Karlsson P, Sun Z, Braun D, et al. Long term results of International Breast Cancer Study Group Trial VIII: adjuvant chemotherapy plus goserelin compared with either therapy alone for premenopausal patients with node-negative breast cancer. Annals of Oncology 2011;22:2216-26

[77] Bianco AR, Del Mastro L, Gallo C, et al. Prognostic role of amenorrhea induced by adjuvant chemotherapy in premenopausal patients with early breast cancer. British Journal of Cancer 1991;63:799-803.

[78] Reyno LM, Levine MN, Skingley P, Skingley P, Arnold A, Abu Zahra H. Chemotherapy induced amenorrhoea in a randomised trial of adjuvant chemotherapy duration in breast cancer. European Journal of Cancer 1993;29:21-3.

[79] Parulekar WR, Day AG, Ottaway JA, et al. Incidence and prognostic impact of amenorrhea during adjuvant therapy in high-risk premenopausal breast cancer: analysis of a National Cancer Institute of Canada Clinical Trials Group Study-NCIC CTG MA.5. Journal of Clinical Oncology 2005;23:6002-8.

[80] Park IH, Han HS, Lee H, et al. Resumption or persistence of menstruation after cytotoxic chemotherapy is a prognostic factor for poor disease-free survival in premenopausal patients with early breast cancer. Annals of Oncology 2012;23:2283-9.

[81] Partridge AH, Gelber S, Peppercorn J, et al. Web-based survey of fertility issues in young women with breast cancer. Journal of Clinical Oncology 2004;22:4174-83.

[82] Lucerna E, Bernal DP, Lucerna C, Rojas A, Moran A, Lucena A. Successful ongoing pregnancies after vitrification of oocytes. Fertility and Sterility 2006;85:108-11.

[83] Dolmans MM, Donnez J, Camboni A, et al. IVF outcome in patients with orthotopically transplanted ovarian tissue. Human Reproduction 2009;24:2778-87.

[84] Vitale AM, Abramovich D, Peluffo MC, Meresman G, Tesone M. Effect of gonadotropin-releasing hormone agonist and antagonist on proliferation and apoptosis of human luteinized granulosa cells. Fertility and Sterility 2006;85:1064.

[85] Emons G, Gründker C, Günthert AR, Westphalen S, Kavanagh J, Verschraegen C. GnRH antagonists in the treatment of gynecological and breast cancers. Endocrine Related Cancer 2003;10:291.

[86] Rugo HS, Rosen MP. Reducing the long-term effects of chemotherapy in young women with early-stage breast cancer. Journal of the American Medical Association 2011;306:312.

[87] Bedaiwy MA, Abou-Setta AM, Desai N, et al. Gonadotropinreleasing hormone analog cotreatment for preservation of ovarian function during gonadotoxic chemotherapy: a systematic review and meta-analysis. Fertility and Sterility 2011;95:906.

[88] Wong M, O’Neill S, Walsh G, Smith IE. Goserelin with chemotherapy to preserve ovarian function in pre-menopausal women with early breast cancer: menstruation and pregnancy outcomes. Annals of Oncology 2013;24:133-8.

[89] Badawy A, Elnashar A, El-Ashry M, Shahat M. Gonadotropinreleasing hormone agonists for prevention of chemotherapy-induced ovarian damage: prospective randomized study. Fertility and Sterility 2009;91:694-7.

[90] Leonard RC, Adamson D, Anderson R, et al. The OPTION trial of adjuvant ovarian protection by goserelin in adjuvant chemotherapy for early breast cancer. Journal of Clinical Oncology 2010;28:89s [Suppl. 15; abstr 590].

[91] Loren AW, Mangu PB, Beck LN, et al. Fertility preservation for patients with cancer: American Society of Clinical Oncology Clinical 
Practice Guideline update. Journal of Clinical Oncology 2013;May, http://dx.doi.org/10.1200/JCO.2013.49.2678.

[92] Domingo J, Guillén V, Ayllón Y, et al. Ovarian response to controlled ovarian hyperstimulation in cancer patients is diminished even before oncological treatment. Fertility and Sterility 2012;97:930-4.

[93] Mertens A, Yasui Y, Neglia J, et al. Late mortality experience in five-year survivors of childhood and adolescent cancer: the childhood cancer survivor study. Journal of Clinical Oncology 2001;19:3163-72.

[94] Partridge A, Gelber S, Gelber RD, Castiglione-Gertsch M, Goldhirsch A, Winer E. Age of menopause among women who remain premenopausal following treatment for early breast cancer: long-term results from International Breast Cancer Study Group Trials V and VI. European Journal of Cancer 2007;43:1646-53.

[95] Lawrenz B, Fehm T, von Wolff M, et al. Centers of FertiPROTEKT Network. Reduced pretreatment ovarian reserve in premenopausal female patients with Hodgkin lymphoma or nonHodgkin-lymphoma-evaluation by using antimüllerian hormone and retrieved oocytes. Fertility and Sterility 2012;98:141-4.

[96] Su HI, Flatt SW, Natarajan L, DeMichele A, Steiner AZ. Impact of breast cancer on anti-mullerian hormone levels in young women. Breast Cancer Research and Treatment 2013;137:571-7.

[97] Lambalk CB, van Disseldorp J, de Koning CH, Broekmans FJ. Testing ovarian reserve to predict age at menopause. Maturitas 2009;63:280-91.

[98] Findlay JK, Drummond AE, Britt KL, et al. The roles of activins, inhibins and estrogen in early committed follicles. Molecular and Cellular Endocrinology 2000;163:81-7.

[99] de Vet A, Laven JS, de Jong FH, Themmen AP, Fauser BC. Antimullerian hormone serum levels: a putative mark of ovarian aging. Fertility and Sterility 2002;77:357-62.

[100] Bath LE, Wallace WH, Shaw MP, Fitzpatrick C, Anderson RA. Depletion of ovarian reserve in young women after treatment for cancer in childhood: detection by anti-Müllerian hormone, inhibin B and ovarian ultrasound. Human Reproduction 2003;18:2368-74.

[101] van Beek RD, van den Heuvel-Eibrink MM, Laven JS. Anti-mullerian hormone is a sensitive serum marker for gonadal function in women treated for Hodgkin's lymphoma during childhood. Journal of Clinical Endocrinology and Metabolism 2007;92:3869-74.

[102] Lie Fong S, Laven JS, Hakvoort-Cammel FG, et al. Assessment of ovarian reserve in adult childhood cancer survivors using antiMüllerian hormone. Human Reproduction 2009;24:982-90.

[103] Lutchman Singh K, Muttukrishna S, Stein RC, et al. Predictors of ovarian reserve in young women with breast cancer. British Journal of Cancer 2007;96:1808-16.

[104] Rosendahl M, Andersen CY, La Cour Freiesleben N, Juul A, Løssl K, Andersen AN. Dynamics and mechanisms of chemotherapy-induced ovarian follicular depletion in women of fertile age. Fertility and Sterility 2010;94:156-66.

[105] Anders C, Marcom PK, Peterson B, et al. A pilot study of predictive markers of chemotherapy-related amenorrhea among premenopausal women with early stage breast cancer. Cancer Investigation 2008;26:286-95.

[106] Su HI, Sammel MD, Green J, et al. Antimullerian hormone and inhibin $\mathrm{B}$ are hormone measures of ovarian function in late reproductive-aged breast cancer survivors. Cancer 2010;116:592-9.

[107] Clemons M, Simmons C. Identifying menopause in breast cancer patients: considerations and implications. Breast Cancer Research and Treatment 2007;104:115-20.

[108] Amir E, Seruga B, Freedman OC, Clemons M. Endocrine therapy for breast cancer: prolonged amenorrhoea is not necessarily indicative of menopause. British Medical Journal 2009;339:b4261.

[109] Wang S, Paris F, Sultan CS, et al. Recombinant cell ultrasensitive bioassay for measurement of estrogens in postmenopausal women. Journal of Clinical Endocrinology and Metabolism 2005;90:1407-13.

[110] Rossi E, Morabito A, Di Rella F, et al. Endocrine effects of adjuvant letrozole compared with tamoxifen in hormone-responsive postmenopausal patients with early breast cancer: the HOBOE trial. Journal of Clinical Oncology 2009;27:3192-7.

[111] Johannessen DC, Engan T, Di Salle E, et al. Endocrine and clinical effects of exemestane (PNU155971), a novel steroidal aromatase inhibitor, in postmenopausal breast cancer patients: a phase I study. Clinical Cancer Research 1997;3:1101-8.

[112] Yu B, Douglas N, Ferin MJ, et al. Changes in markers of ovarian reserve and endocrine function in young women with breast cancer undergoing adjuvant chemotherapy. Cancer 2010;116:2099-105.

[113] Anderson RA, Cameron DA. Pretreament serum anti-mullerian hormone predicts long-term ovarian function and bone mass after chemotherapy for early breast cancer. Journal of Clinical Endocrinology and Metabolism 2011;96:1336-43.

[114] Torino F, Barnabei A, De Vecchis L, Appetecchia M, Strigari L, Corsello SM. Recognizing menopause in women with amenorrhea induced by cytotoxic chemotherapy for endocrine-responsive early breast cancer. Endocrine Related Cancer 2012;19:21-33.

[115] Geisler J, Ekse D, Helle H, Duong NK, Lønning PE. An optimised, highly sensitive radioimmunoassay for the simultaneous measurement of estrone, estradiol and estrone sulfate in the ultra-low range in human plasma samples. Journal of Steroid Biochemistry and Molecular Biology 2008;109:90-5.

[116] Lee SJ, Schover LR, Partridge AH, et al. American Society of Clinical Oncology recommendations on fertility preservation in cancer patients. Journal of Clinical Oncology 2006;24:2917-31.

[121] Chang TK, Weber GF, Crespi CL, Waxman DJ. Differential activation of cyclophosphamide and ifosphamide by cytochromes P-450 2B and 3A in human liver microsomes. Cancer Research 1993;53:5629-37.

[122] Tsai-Turton M, Luong BT, Tan Y, Luderer U. Cyclophosphamideinduced apoptosis in COV434 human granulosa cells involves oxidative stress and glutathione depletion. Toxicological Sciences 2007;98:216-30

[123] Marcello MF, Nuciforo G, Romeo R, et al. Structural and ultrastructural study of the ovary in childhood leukemia after successful treatment. Cancer 1990;66:2099-104.

[124] Meirow D, Dor J, Kaufman B, et al. Cortical fibrosis and blood-vessels damage in human ovaries exposed to chemotherapy. Potential mechanisms of ovarian injury. Human Reproduction 2007;22:1626-33.

[125] Devine PJ, Perreault SD, Luderer U. Roles of reactive oxygen species and antioxidants in ovarian toxicity. Biology of Reproduction 2012;86:27.

[126] Higdon RE, Marchetti F, Mahies JB, Philips GL. The effects of cisplatin on murine metaphase II oocytes. Gynecologic Oncology 1992;147:348-52.

[127] Yeh J, Kim BS, Pereseie J, Page C. Declines in levels of hyperpolarization-activated cation $(\mathrm{HCN})$ channels in the rat ovary after cisplatin exposure. Reproductive Sciences 2009;16:986-94.

[128] Yeh J, Kim BS, Liang YJ, Peresie J. Baseline and stimulated serum inhibin levels as biomarkers of cisplatin-induced ovarian damage in female rats. American Journal of Obstetrics and Gynecology 2008;198:e1-6.

[129] Gonfloni S, Di Tella I, Caldarola S, et al. Inhibition of the c-AblTAp63 pathway protects mouse oocytes from chemotherapy-induced death. Nature Medicine 2009;15:1179-85.

[130] Perez GI, Knudson CM, Leykin L, Korsmeyer SJ, Tilly JL. Apoptosis-associated signaling pathways are required for chemotherapy-mediated female germ cell destruction. Nature Medicine 1997;3:1228-32.

[131] Perez GI, Tao XJ, Tilly JL. Fragmentation and death (a.k.a. apoptosis) of ovulated oocytes. Molecular Human Reproduction 1999;5:414-20.

[132] Takai Y, Matikainen T, Jurisicova A, et al. Caspase-12 compensates for lack of caspase-2 and caspase-3 in female germ cells. Apoptosis 2007; 12:791-800.

[133] Ting AY, Petroff BK. Tamoxifen decreases ovarian follicular loss from experimental toxicant DMBA and chemotherapy agents cyclophosphamide and doxorubicin in the rat. Journal of Assisted Reproduction and Genetics 2010;27:591-7. 
[134] Soleinmani R, Heytens E, Darzynkiewicz Z, Oktay K. Mechanisms of chemotherapy-induced human ovarian aging: double strand DNA breaks and microvascular compromise. Aging 2011;3: 782-93.

[135] Ben-Aharon I, Bar-Joseph H, Tzarfaty G, et al. Doxorubicininduced ovarian toxicity. Reproductive Biology and Endocrinology 2010;4:8-20.

[136] Tarumi W, Suzuki N, Takahashi N, et al. Ovarian toxicity of paclitaxel and effect on fertility in the rat. Journal of Obstetrics and Gynaecology Research 2009;35:414-20.

[137] Hrushesky WJ, Vyzula R, Wood PA. Fertility maintenance and 5-fluorouracil timing within the mammalian fertility cycle. Reproductive Toxicology 1999;12:413-20.

\section{Biographies}

Francesco Torino received his Medical Degree in 1989 from Catholic University of Rome, Italy; in 1994 he specialized in Internal Medicine, Catholic University of Rome, and in 2002 in Medical Oncology, Tor Vergata University of Rome. He is an Assistant Professor of Medical Oncology at the Department of Systems Medicine - Chair of Medical Oncology, at the Tor Vergata University of Rome. He has authored/coauthored more than 30 papers published in peerreviewed international journals and 10 book chapters. Current areas of research include endocrine treatment-related toxicity of targeted and cytotoxic agents, evaluation of new predictive factors of resistance in colorectal cancer, cancer autophagy and the clinical utility of circulating tumor cells in colorectal cancer.

Agnese Barnabei received her Medical Degree in 1993 from Catholic University of Rome, Italy; in 1998 she specialized in Endocrinology, Catholic University of Rome, and in 2010 in Medical Oncology, Tor Vergata University of Rome. She is a Senior Assistant at the Endocrinology Unit, Department of Oncology Prevention of National Institute of Cancer "Regina Elena" of Rome. She has authored/coauthored circa 20 papers published in peer-reviewed international journals and several book chapters. Current areas of research include endocrine treatment-related toxicity of targeted and cytotoxic agents and innovative therapeutic approaches of thyroid, adrenal and neuroendocrine cancer.
Valentina Sini received her Medical Degree in 2006 from "Tor Vergata" University of Rome, Italy. In 2011 she specialized in Oncology, "Tor Vergata" University of Rome. Since 2011 she is a PhDs in PhD University Grant program "Clinical and Experimental Research Methodologies in Oncology" provided by the Faculty of Medicine and Psychology, "Sapienza" University of Rome. She is an assistant at the Oncology Unit, Department of Oncology "Sant'Andrea" of Rome. She authored/coauthored 5 papers published in peer-reviewed international journals. Current areas of research include new treatments of breast cancer, cardiac and endocrine-related toxicity of targeted and cytotoxic agents, optimization of endocrine therapy in breast cancer.

Paolo Marchetti is currently a Full Professor of Medical Oncology, Chief of Medical Oncology at Sant'Andrea Hospital, Rome, Director of Postgraduate Course in Oncology, Director of II Level Master in Psycho-oncology and Relationship with the Patient. Medical Consultant for IDI - IRCCS (recognized by the Italian Ministry of Health as a Scientific Institute carrying out biomedical research and clinical activities of relevant national interest), Rome, Italy. Principal areas of research: alterations of hormone receptor status in hormone related tumors and their clinical implications on prognosis and therapy; chemoprevention of breast cancer; familial/hereditary breast cancer and BRCA1/2 mutations; clinical implications of the inactivation of tumor suppressor genes in solid tumors; innovative molecular scanning techniques for the detection of gene mutations; treatment of breast cancer, melanoma, lung, colorectal and gynecological cancers; palliative care in cancer patients.

Salvatore M. Corsello received his Medical Degree from the Catholic University of Rome in 1978. He then specialized in Internal Medicine and Endocrinology at the same University. He was Honorary Clinical Assistant at St Bartholomew's Hospital in London for one year (1987). He is presently an Associate Professor of Endocrinology at the Catholic University in Rome. He is an active member of the Endocrine Society, and has published circa 90 peer-reviewed papers and more than 300 other publications, with a focus on pituitary and thyroid diseases. 